\title{
The Inverse Association of Plasma Lipoprotein(a) Concentrations with Apolipoprotein (a) Isoform Size Is Not Due to Differences in Lp(a) Catabolism but to Differences in Production Rate
}

Daniel J. Rader, William Cain, Katsunori Ikewaki, Glenda Talley, Loren A. Zech, David Usher, and H. B. Brewer, Jr. Molecular Disease Branch National Heart, Lung, and Blood Institute, National Institutes of Health Bethesda, Maryland 20892

\begin{abstract}
Lipoprotein(a) (Lp[a]) is an atherogenic lipoprotein which is similar in structure to low density lipoproteins (LDL) but contains an additional protein called apolipoprotein(a) (apo[a]). Apo(a) is highly polymorphic in size, and there is a strong inverse association between the size of the apo(a) isoform and the plasma concentration of $\operatorname{Lp}(\mathrm{a})$. We directly compared the in vivo catabolism of $L p(a)$ particles containing different size apo(a) isoforms to establish whether there is an effect of apo(a) isoform size on the catabolic rate of $\operatorname{Lp}(a)$. In the first series of studies, four normal subjects were injected with radiolabeled S1-Lp (a) and S2-Lp (a) and another four subjects were injected with radiolabeled S2-Lp(a) and S4-Lp(a). No significant differences in fractional catabolic rate were found between Lp(a) particles containing different apo(a) isoforms. To confirm that apo(a) isoform size does not influence the rate of Lp(a) catabolism, three subjects heterozygous for apo(a) were selected for preparative isolation of both $\operatorname{Lp}(\mathrm{a})$ particles. The first was a B/S3-apo(a) subject, the second a S4/S6-apo(a) subject, and the third an F/S3-apo(a) subject. From each subject, both $L p(a)$ particles were preparatively isolated, radiolabeled, and injected into donor subjects and normal volunteers. In all cases, the catabolic rates of the two forms of $L p(a)$ were not significantly different. In contrast, the allele-specific apo(a) production rates were more than twice as great for the smaller apo (a) isoforms than for the larger apo(a) isoforms. In a total of 17 studies directly comparing $L p(a)$ particles of different apo(a) isoform size, the mean fractional catabolic rate of the $L p$ (a) with smaller size apo (a) was $0.329 \pm 0.090$ day $^{-1}$ and of the $L p(a)$ with the larger size apo(a) $0.306 \pm 0.079 \mathrm{day}^{-1}$, not significantly different. In summary, the inverse association of plasma $\operatorname{Lp}(\mathrm{a})$ concentrations with apo(a) isoform size is not due to differences in the catabolic rates of $\operatorname{Lp}(a)$ but rather to differences in Lp(a) production rates. (J. Clin. Invest. 1994. 93:2758-2763.) Key words: lipoprotein(a) • apolipoprotein(a) - atherosclerosis $\bullet$ lipoproteins $\bullet$ kinetics
\end{abstract}

Address correspondence to D. J. Rader, Institute for Human Gene Therapy, University of Pennsylvania Medical Center, 601 Maloney, 3400 Spruce St., Philadelphia, PA 19104-4283.

D. Usher's and W. Cain's present address is School of Life and Health Sciences, University of Delaware, Newark, DE 19716.

Received for publication 15 October 1993 and in revised form 25 January 1994.

The Journal of Clinical Investigation, Inc.

Volume 93, June 1994, 2758-2763

\section{Introduction}

Lipoprotein (a) $(\operatorname{Lp}[a])^{1}$ is an atherogenic lipoprotein particle in human plasma related in structure to low density lipoproteins (LDL) (1). Elevated plasma $L p(a)$ concentrations are associated with an increased risk of premature coronary heart disease (CHD) (2-6). Lp (a) levels are predictive of the extent of angiographically documented CHD independently of LDL cholesterol levels (7), although the relative risk of elevated $\mathrm{Lp}$ (a) concentrations is significantly increased in patients who also have high levels of LDL cholesterol $(8,9)$. One study estimated that the population attributable risk of CHD due to elevated $\mathrm{Lp}(\mathrm{a})$ levels was $\sim 25 \%$ in men under $60 \mathrm{yr}$ old $(10)$. Family studies in a group of 102 probands with premature CHD indicated that $L p(a)$ excess was the most frequent familial lipoprotein disorder found in this cohort with premature CHD (11). It has been suggested that Lp(a) levels may account for most of the familial predisposition to premature CHD which cannot be accounted for by other known risk factors including LDL and HDL cholesterol levels (12).

$\mathrm{Lp}(\mathrm{a})$ is an LDL-like lipoprotein consisting of lipids and apoB-100, but differs from LDL in that it contains an additional protein called apolipoprotein(a) (apo[a]). Apo(a) is thought to be covalently linked to apoB via a disulfide bridge $(13,14)$, but can also associate noncovalently with apoB $(15$, 16). $\mathrm{Lp}(\mathrm{a})$ concentrations are strongly genetically determined (17), with at least $90 \%$ of the variation determined by variation within the gene for apo(a) (18). One important factor determining plasma $\operatorname{Lp}(\mathrm{a})$ levels is the apo(a) isoprotein phenotype, with a strong inverse correlation between the size of the apo (a) isoprotein and the $\mathrm{Lp}(\mathrm{a})$ concentration (19). To establish the mechanism by which apo(a) isoform size affects plasma $\mathrm{Lp}(\mathrm{a})$ concentrations, we performed a series of in vivo kinetic studies in humans directly comparing the metabolism of $\operatorname{Lp}(\mathrm{a})$ particles containing apo(a) isoproteins of different sizes.

\section{Methods}

Study subjects. 17 subjects participated in the studies. All subjects had normal fasting plasma glucose levels, and normal thyroid, liver, and renal function. They were free of illness and were on no medications. All subjects gave informed consent and the study protocol was approved by the Institutional Review Board of the National Heart Lung and Blood Institute.

1. Abbreviations used in this paper: apo(a), apolipoprotein(a); CHD, coronary heart disease; $\operatorname{Lp}(\mathrm{a})$, lipoprotein(a). 
Isolation and iodination of $\operatorname{Lp}(a)$. For the first series of studies, $\mathrm{Lp}$ (a) particles were isolated from the fasting plasma of healthy subjects with one identifiable apo(a) isoform in plasma. SI-Lp(a) particles were isolated from an individual with a plasma $\operatorname{Lp}(\mathrm{a})$ level of 53 $\mathrm{mg} / \mathrm{dl}, \mathrm{S} 2-\mathrm{Lp}$ (a) particles were isolated from an individual with a level of $91 \mathrm{mg} / \mathrm{dl}$, and S4-Lp(a) particles were isolated from an individual with a level of $36 \mathrm{mg} / \mathrm{dl}$. Plasma was obtained after a 12-h fast and NaEDTA $(0.01 \%)$, sodium azide $(0.05 \%)$, and DFP $(1 \mathrm{mM})$ were added. $\mathrm{Lp}(\mathrm{a})$ was isolated according to the procedure described by Fless et al. (13). Plasma was adjusted to a density of $1.21 \mathrm{~g} / \mathrm{ml}$ using solid $\mathrm{NaBr}$ and ultracentrifuged for $48 \mathrm{~h}$ to isolate total plasma lipoproteins. The $d<1.21 \mathrm{~g} / \mathrm{ml}$ fraction was adjusted to $d=1.4 \mathrm{~g} / \mathrm{ml}$ with $\mathrm{NaBr}$ and ultracentrifuged on a $0-30 \% \mathrm{NaBr}$ density gradient in order to remove HDL. The fraction containing $\operatorname{Lp}(\mathrm{a})$ was then adjusted to a concentration of $7.5 \% \mathrm{CsCl}$ and ultracentrifuged for $30 \mathrm{~h}$ to separate Lp(a) from VLDL and LDL. Residual LDL was eliminated by chromatofocusing on a PBE94 column (Pharmacia, Uppsala, Sweden) within a $\mathrm{pH}$ range of 7.0 to 4.0 .

In the second series of studies, three subjects who each had two clearly identifiable plasma apo(a) isoforms were used for preparative $\mathrm{Lp}$ (a) isolation. Plasma was adjusted to a density of $1.21 \mathrm{~g} / \mathrm{ml}$ using solid $\mathrm{NaBr}$ and ultracentrifuged for $48 \mathrm{~h}$ to isolate total plasma lipoproteins. Lipoproteins were dialyzed vs. $0.1 \mathrm{M}$ phosphate buffer, $\mathrm{pH} 7.4$, with $0.01 \% \mathrm{Na}_{2}$ EDTA, $0.01 \% \mathrm{NaN}_{3}$, and $1 \mathrm{mM}$ benzamidine and then passed over a lysine-sepharose 4B column (Sigma Chemical Co., St. Louis, MO). The column was washed with the same phosphate buffer and then bound material was eluted with $20 \mathrm{mM}$ epsilon amino caproic acid (EACA) in the same phosphate buffer. Eluted material was adjusted to a concentration of $7.5 \% \mathrm{CsCl}$ and ultracentrifuged for $30 \mathrm{~h}$ at $45,000 \mathrm{rpm}$ to separate the two classes of $\mathrm{Lp}(\mathrm{a})$ particles containing the two different apo(a) isoforms. The apo(a) isoform affects the density of the $\operatorname{Lp}(\mathrm{a})$ particle, as previously shown by us (20) and others (21), allowing effective separation of particles by density. Isolated $\mathrm{Lp}$ (a) was analyzed for purity by reducing and nonreducing SDSPAGE and by $0.6 \%$ agarose electrophoresis (Helena Laboratories, Beaumont, TX).

All $L p(a)$ samples were extensively dialyzed against PBS with $0.01 \%$ EDTA before iodination using a modification of the iodine monochloride method (22). Briefly, an equal volume of a $1 \mathrm{M}$ glycine buffer was added to the $\mathrm{Lp}(\mathrm{a})$ sample. $5 \mathrm{mCi}{ }^{125} \mathrm{I}$ or ${ }^{131} \mathrm{I}$ were then added, followed by ICI. Approximately one mole of iodine was incorporated per mole of $L p(a)$. Samples were dialyzed extensively against PBS $/ 0.01 \%$ EDTA to remove free iodine. Human serum albumin was added to a final concentration of 5\% (wt/ vol), samples were sterile-filtered through a $0.22-\mu \mathrm{m}$ filter and tested for pyrogens and sterility before injection. Iodinated $L p(a)$ particles were evaluated by SDSPAGE and agarose electrophoresis.

Table I. Characteristics of Study Subjects

\begin{tabular}{|c|c|c|c|c|c|c|}
\hline Subjects & Sex & Age & BMI & TG & Chol & $\mathbf{L P}(\mathbf{a})$ \\
\hline & & $y r$ & $\mathrm{~kg} / \mathrm{m}^{2}$ & & $m g / d l$ & \\
\hline \multicolumn{7}{|l|}{ Series 1} \\
\hline \multicolumn{7}{|c|}{ Normal subjects $(n=8)$} \\
\hline Mean & & 24 & 25.0 & 93 & 167 & 18 \\
\hline SD & & 3 & 3.1 & 29 & 28 & 30 \\
\hline \multicolumn{7}{|l|}{ Series 2} \\
\hline \multicolumn{7}{|c|}{ Apo(a) heterozygotes } \\
\hline 1 & $\mathbf{F}$ & 72 & 26.2 & 80 & 214 & 197 \\
\hline 2 & $\mathbf{M}$ & 76 & 22.2 & 77 & 199 & 153 \\
\hline 3 & $\mathbf{F}$ & 65 & 24.6 & 202 & 270 & 133 \\
\hline \multicolumn{7}{|c|}{ Normal subjects $(n=6)$} \\
\hline Mean & & 21 & 23.6 & 77 & 170 & 15 \\
\hline SD & & 2 & 2.4 & 29 & 21 & 21 \\
\hline
\end{tabular}

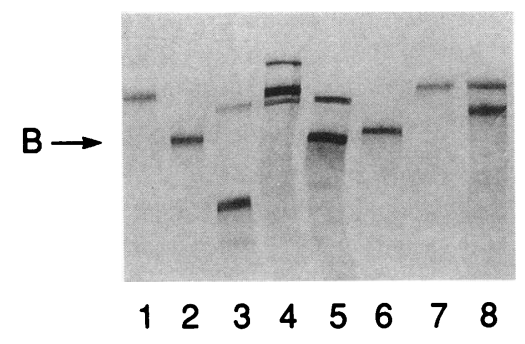

Figure 1. Immunoblot of plasma apo(a) from three heterozygous apo(a) subjects who served as donors for $\mathrm{Lp}$ (a) particle isolations and several apo(a) standards. Lane $1, \mathrm{~S} 3$ standard; lane 2, B standard; lane 3, subject 3 (F/S3); lane 4, sub-

ject 2 (S4/S6) lane 5, subject 1 (B/S3); lane 6, S1 standard; lane 7, $\mathrm{S} 4$ standard; and lane $8, \mathrm{~S} 2 / \mathrm{S} 4$ standard. The $B$ at left marks the position of apoB-100 and the apo(a)-B isoform.

Study protocol. Subjects were permitted to eat a normal diet but were instructed not to drink alcoholic beverages for $1 \mathrm{wk}$ before and during the study. $1 \mathrm{~d}$ before injection, the subjects were given potassium iodide at a dose of $900 \mathrm{mg} / \mathrm{d}$ in divided doses and this was continued for the duration of the study. Radioiodinated $L p(a)$ was injected after a 12-h fast. Blood samples were obtained $10 \mathrm{~min}$ after injection and then at $1,3,6,12$, and $24 \mathrm{~h}$, and at $2,3,4,5,7,9,11$, and $14 \mathrm{~d}$. Blood was drawn into tubes containing EDTA at a final concentration of $0.1 \%$, immediately placed at $4^{\circ} \mathrm{C}$, and plasma was separated by lowspeed centrifugation in a refrigerated centrifuge. Sodium azide and aprotinin were added to plasma at a final concentration of $0.05 \%$ and $200 \mathrm{KIU} / \mathrm{ml}$, respectively. Radioactivity in 4-ml plasma aliquots was quantitated in a Packard Cobra gamma counter (Packard Instrument Co., Downers Grove, IL). Plasma curves were constructed by dividing the plasma radioactivity at each time point by the plasma radioactivity at the initial 10-min time point. The fractional catabolic rates (FCRs) were obtained from the plasma radioactivity curves using a multi-exponential curve-fitting technique (23). Production rates (PR) were determined using the formula: $P R=[(\operatorname{Lp}(a)$ concentration $) \times(F C R)$ $\times$ (plasma volume) $] /$ (body weight). Plasma volume was assumed to be $4 \%$ of body weight.

Apo (a) immunoblotting. Apo(a) isoform determination was performed on whole plasma using a sensitive immunoblotting technique previously described (20). Briefly, plasma samples were delipidated twice in chloroform-methanol 8:5 ( vol/vol) and washed twice with phosphate buffered saline. Samples were reduced with $100 \mathrm{mM}$ dithiothreitol in $8 \mathrm{M}$ urea, incubated at $37^{\circ} \mathrm{C}$ for $30 \mathrm{~min}$, and solubilized in $40 \mu \mathrm{l} 0.02 \mathrm{M}$ ethylmorpholine containing 10\% SDS. Samples were applied to $7.5 \%$ polyacrylamide gel electrophoresis with $0.1 \%$ crosslinker (24) and run for $\sim 4.5 \mathrm{~h}$ at $20 \mathrm{~mA}$. After electrotransfer of the proteins to Immobilon PVDF transfer membranes (Millipore Corp., Bedford, MA), membranes were incubated with a 1:2,000 dilution of a monoclonal anti-apo(a) antibody (2D1; Cappel Laboratories, Durham, NC) and detected with the Vectastain ABC anti-mouse IgG test kit ( Vector Laboratories, Burlingame, CA). Several plasma samples of known apo(a) isoform were used as calibration standards. In the apo(a) heterozygotes, the relative quantities of the two apo(a) isoforms were determined by laser scanning densitometry.

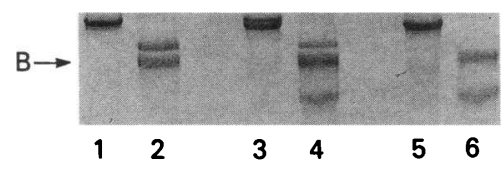

Figure 2. Nonreducing and reducing SDSPAGE of purified $\operatorname{Lp}(\mathrm{a})$ particles from heterozygous apo(a) $-\mathrm{F} / \mathrm{S} 3$ subject No. 3. Lanes 1,3 ,

and 5 are nonreducing; lanes 2,4 , and 6 are reducing. Lanes 1 and 2 , $\mathrm{Lp}(\mathrm{a})$ containing apo(a)-S3 isoform; lanes 5 and $6, \mathrm{Lp}(\mathrm{a})$ containing apo (a)-F isoform; lanes 3 and 4 , mixture of both purified $\mathrm{Lp}(\mathrm{a})$ particles. The $B$ at left marks the position of apoB-100 and the apo(a)-B isoform. 
A

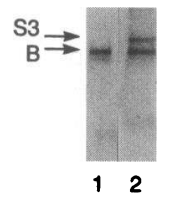

B

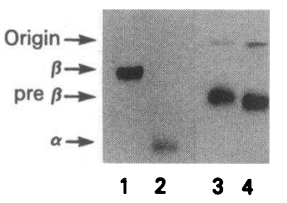

Figure 3. $(A)$ Reducing SDS-PAGE of radioiodinated $\mathrm{Lp}(\mathrm{a})$ isolated from heterozygous subject 1: lane 1, B-Lp(a) with single band in $B$ position representing both B-apo(a) and apoB; lane 2, S3-Lp(a) showing both labeled apo(a) (upper band) and labeled apoB (lower band). ( $B$ ) Nondenaturing agarose electrophoresis of radioiodinated $\mathrm{Lp}(\mathrm{a})$ isolated from the same subject: lane 1, LDL standard; lane 2, HDL standard; lane 3, B-Lp(a); lane 4, S3-Lp(a).

Analytical methods. Plasma cholesterol and triglycerides were quantitated by automated enzymatic techniques on an Abbott VPSS analyzer (Abbott Laboratories, North Chicago, IL). Plasma apoB concentrations were determined by ELISA as previously described (25). Plasma $\operatorname{Lp}(\mathrm{a})$ concentrations were determined by a differential ELISA based on the method of Fless et al. (26), as previously described (22). Briefly, a monoclonal antibody against apo(a) (2D1; Cappel Laboratories) was used to coat microtiter plates at a concentration of $10 \mu \mathrm{g} / \mathrm{ml}$. After blocking with $5 \%$ sucrose and $2 \%$ BSA, plasma samples at a 1:5,000 dilution were added to wells and incubated for $60 \mathrm{~min}$ at $37^{\circ} \mathrm{C}$. A sheep polyclonal anti-apoB (Biodesign, Kennebunkport, ME) labeled with horseradish peroxidase was added to the wells at a 1:5,000 dilution and incubated for $60 \mathrm{~min}$. Substrate was then added and absorbance read at $450 \mathrm{~nm}$. The standard was a secondary plasma standard calibrated against two commercial $L p(a)$ standards (Terumo, Elkton, MD; and Immuno, Austria). Two controls were run with each assay. Intra- and interassay CV's were $<3 \%$ and $<10 \%$, respectively.

\section{Results}

Characterization of study subjects. The clinical and lipid data on the study subjects are presented in Table I. Values are the mean of at least five fasting determinations made during the metabolic study. Immunoblots of plasma apo(a) in the three apo(a) heterozygotes who participated in these studies are shown in Fig. 1.

Analysis of $L p(a)$. Preparatively isolated $L p(a)$ was analyzed by reducing and nonreducing SDS-PAGE. A representative Coomassie blue-stained gel of the two $\mathrm{Lp}(\mathrm{a})$ particles isolated from one of the heterozygous subjects (apo[a]-F/S3) is illustrated in Fig. 2. The nonreduced lanes demonstrate the absence of apoB not complexed to apo(a). The reduced lanes demonstrate the purity of the isolations, each limited to only one apo(a) isoform plus the accompanying apoB. Electrotransfer and immunoblotting with an apo(a)-specific antibody confirmed the bands as apo(a). Radiolabeled $\mathrm{Lp}$ (a) particles were analyzed by SDS-PAGE and by agarose electrophoresis (Fig. 3). In all cases, radiolabeled apo(a) and apoB were intact and not degraded, and radiolabeled $\operatorname{Lp}(\mathrm{a})$ was found to $\mathrm{mi}-$ grate only in the prebeta region.

Metabolism of $L p(a)$. The first series of studies involved the isolation of $\operatorname{Lp}(\mathrm{a})$ particles from individuals with only one apo (a) isoform and direct comparison of the kinetics of $\mathrm{Lp}(\mathrm{a})$ particles containing different apo(a) isoforms isolated from different subjects. These studies indicated that the fractional catabolic rates of S1-Lp(a), S2-Lp(a), and S4-Lp(a) were not significantly different (Table II). However, the $\mathrm{Lp}(\mathrm{a})$ particles used for these studies were isolated from different individuals.

Table II. Fractional Catabolic Rates of Lp(a) Particles with Different Apo(a) Isoforms

\begin{tabular}{|c|c|c|c|c|c|c|c|c|c|}
\hline & $\begin{array}{c}\text { Apo(a) } \\
\text { phenotype }\end{array}$ & $\mathbf{F}$ & B & S1 & S2 & S3 & S4 & S6 & Diff* \\
\hline & & \multicolumn{8}{|c|}{ day $^{-1}$} \\
\hline \multicolumn{10}{|c|}{ Series 1} \\
\hline 1 & S2 & & & 0.420 & 0.394 & & & & 0.026 \\
\hline 2 & S4 & & & 0.416 & 0.361 & & & & 0.055 \\
\hline 3 & S4 & & & 0.461 & 0.393 & & & & 0.068 \\
\hline 4 & S4 & & & 0.443 & 0.374 & & & & 0.069 \\
\hline 5 & $\mathbf{S} 2$ & & & & 0.244 & & 0.213 & & 0.031 \\
\hline 6 & $\mathbf{S} 2$ & & & & 0.281 & & 0.258 & & 0.023 \\
\hline 7 & S4 & & & & 0.242 & & 0.222 & & 0.020 \\
\hline 8 & S4 & & & & 0.266 & & 0.246 & & 0.020 \\
\hline \multicolumn{10}{|c|}{ Series 2} \\
\hline $1^{\ddagger}$ & $\mathrm{B} / \mathrm{S} 3$ & & 0.251 & & & 0.266 & & & -0.015 \\
\hline $1-1$ & S3/S5 & & 0.359 & & & 0.373 & & & -0.014 \\
\hline $1-2$ & S1/S5 & & 0.360 & & & 0.382 & & & -0.022 \\
\hline $2^{\ddagger}$ & S4/S6 & & & & & & 0.211 & 0.195 & 0.016 \\
\hline $3^{\ddagger}$ & F/S3 & 0.257 & & & & 0.303 & & & -0.046 \\
\hline $3-1$ & S5/S6 & 0.288 & & & & 0.338 & & & -0.050 \\
\hline $3-2$ & S4/S5 & 0.289 & & & & 0.322 & & & -0.033 \\
\hline $3-3$ & 0 & 0.289 & & & & 0.330 & & & -0.041 \\
\hline $3-4$ & S6 & 0.308 & & & & 0.338 & & & -0.030 \\
\hline Mean & & 0.286 & 0.323 & 0.435 & 0.319 & 0.332 & 0.230 & 0.195 & $0.005^{\S}$ \\
\hline SD & & 0.018 & 0.063 & 0.021 & 0.067 & 0.037 & 0.021 & - & 0.039 \\
\hline
\end{tabular}

In Series 1, three different homozygous individuals were the donors for the S1, S2, and S4-Lp(a) particles. * Difference: FCR of smaller apo(a) isoform minus FCR of larger apo(a) isoform. ${ }^{\ddagger}$ Heterozygous apo(a) subjects who were donors for isolated Lp(a) particles in Series 2 . ${ }^{8}$ Not different from zero by paired $t$ test. 
Therefore, in the second series of studies, we preparatively isolated both types of $\operatorname{Lp}(\mathrm{a})$ particles from three subjects who each had two identifiable apo(a) isoforms in plasma. In all cases, the smaller apo(a) isoform was in substantially higher plasma concentration than the larger apo(a) isoform by apo (a) immunoblotting (Fig. 1). The two $\mathrm{Lp}(\mathrm{a})$ particles isolated from the same individual were then radiolabeled and injected back into the same subject, and in some cases into other control subjects. The $\operatorname{Lp}(\mathrm{a})$ plasma curves in the three heterozygous apo (a) subjects whose autologous $\mathrm{Lp}(\mathrm{a})$ particles were isolated, labeled, and reinjected are illustrated in Fig. 4. In all cases, there was no difference in the catabolism of the two forms of $\operatorname{Lp}(\mathrm{a})$ in the three heterozygotes (Fig. 4) as well as in the control subjects. The fractional catabolic rates of $\operatorname{Lp}(a)$ for all studies are provided in Table II. The mean difference in FCR between the two $\operatorname{Lp}(\mathrm{a})$ particles of different apo(a) isoform was not significantly different from zero by paired $t$ test. These results indicate that the size of the apo(a) isoform did not affect the in vivo catabolism of its associated $\mathrm{Lp}(\mathrm{a})$ particle.

In the three heterozygous subjects, the relative plasma concentrations of the two apo(a) isoforms were estimated by densi-

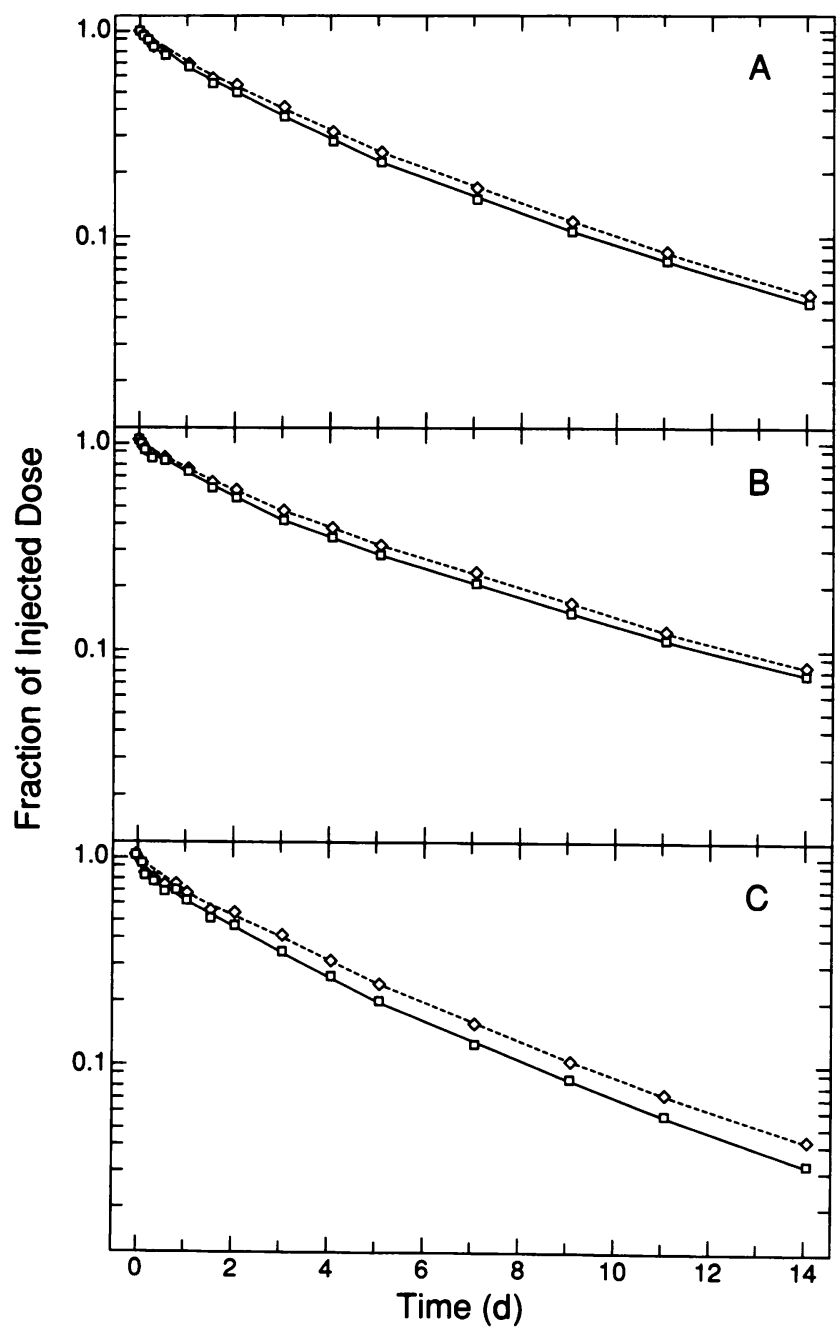

Figure 4. Plasma radioactivity curves of autologous radiolabeled $\mathrm{Lp}$ (a) particles isolated from heterozygous apo(a) subjects and injected back into the same subjects. $(A)$ subject no. $1,(B)$ subject no. $2,(C)$ subject no. 3 .
Table III. Lp(a) Kinetic Parameters in Heterozygous Apo(a) Subjects

\begin{tabular}{|c|c|c|c|c|c|}
\hline \multirow[b]{2}{*}{ Subject } & \multirow{2}{*}{$\begin{array}{l}\text { Apo(a) } \\
\text { isoform }\end{array}$} & \multicolumn{3}{|c|}{$\mathrm{Lp}(\mathrm{a})$} & \multirow{2}{*}{$\begin{array}{c}\mathrm{PR} \\
\text { ratio }^{*}\end{array}$} \\
\hline & & conc & FCR & PR & \\
\hline & & $m g / d l$ & $d a y^{-1}$ & $\mathrm{mg} / \mathrm{kg}-\mathrm{d}$ & \\
\hline \multirow[t]{2}{*}{1} & B & 134 & 0.251 & 13.4 & 2.0 \\
\hline & S3 & 62 & 0.266 & 6.6 & \\
\hline \multirow[t]{2}{*}{2} & S4 & 106 & 0.211 & 8.9 & 2.4 \\
\hline & S6 & 47 & 0.195 & 3.7 & \\
\hline \multirow[t]{2}{*}{3} & $F$ & 99 & 0.257 & 10.2 & 2.5 \\
\hline & S3 & 34 & 0.303 & 4.1 & \\
\hline
\end{tabular}

* Ratio of the production rates of the smaller/larger apo(a) isoform.

tometric scanning of plasma apo(a) immunoblots and isoform-specific $\operatorname{Lp}(\mathrm{a})$ production rates were determined. In all three subjects, the production rate of the smaller apo(a) isoprotein was substantially greater than that of the larger apo(a) isoprotein (Table III).

\section{Discussion}

The inverse association of apo(a) isoprotein size and plasma $\mathrm{Lp}$ (a) concentration is well established (17-19). By apo(a) genotyping, the apo(a) size polymorphism has been estimated to account for $\sim 70 \%$ of the variation in $\operatorname{Lp}(\mathrm{a})$ plasma levels (18). Because the physiologic basis for this inverse association has not been elucidated, we undertook a series of $L p(a)$ kinetic studies in humans to determine whether apo(a) isoform size affects $\operatorname{Lp}(\mathrm{a})$ catabolic or $\mathrm{Lp}(\mathrm{a})$ production rates.

In a series of eight normal subjects we established that S2$\mathrm{Lp}(\mathrm{a})$ was not catabolized at a different rate than S1-Lp(a) or S4-Lp(a). To confirm that apo(a) isoform size does not affect $\mathrm{Lp}(\mathrm{a})$ catabolic rate, we then isolated $\mathrm{Lp}(\mathrm{a})$ from three subjects who had two distinct apo(a) bands on protein phenotyping. The size of the apo(a) isoprotein determines the density of the $\operatorname{Lp}(\mathrm{a})$ particle $(20,21)$, and this difference in density can be used to preparatively isolate $\operatorname{Lp}(\mathrm{a})$ particles containing different apo (a) isoproteins from the same heterozygous individual. In all cases, the catabolic rates of the two different $L p(a)$ particles were not significantly different, establishing that apo(a) protein size has no effect on the catabolic rate of its associated $\mathrm{Lp}(\mathrm{a})$ particle. Apo(a) isoform-specific production rates were determined in the three heterozygous subjects and were substantially higher for the smaller size apo(a) alleles. Therefore, the apo (a) size polymorphism does not affect catabolism of $\operatorname{Lp}(\mathrm{a})$ but rather is associated with variation in $\operatorname{Lp}(\mathrm{a})$ production.

Krempler et al. (27) reported the turnover of autologous $\mathrm{Lp}(\mathrm{a})$ in a series of nine subjects and found a correlation between $\mathrm{Lp}(\mathrm{a})$ level and production rate, but the study subjects were of undefined apo(a) phenotype. Knight et al. (28) reported the turnover of autologous $\operatorname{Lp}(\mathrm{a})$ in eight subjects of variable apo(a) phenotype and also found a correlation between $\operatorname{Lp}(\mathrm{a})$ level and production rate, but did not directly compare the metabolism of different apo(a) isoforms. We recently reported that differences in $\operatorname{Lp}(\mathrm{a})$ among individuals with the same apo(a) isoform are due to variation in $\operatorname{Lp}(a)$ production, not catabolism (22). These studies now establish 
that the effect of apo (a) isoform size on $\operatorname{Lp}(\mathrm{a})$ concentration is also mediated through modulation of $\mathrm{Lp}(\mathrm{a})$ production, not catabolism.

A few potential limitations to the interpretation of these studies should be mentioned. First, only individuals with high plasma levels of $L p(a)$ were used as donors for the isolation of $L p(a)$ particles, in order to obtain enough pure $L p(a)$ to perform the kinetic studies. However, because these studies involved the direct comparison of two different apo(a) isoforms in the same individual, the fact that the $\operatorname{Lp}(a)$ particles were isolated from individuals with high levels is unlikely to have biased the results. Second, lysine-sepharose affinity chromatography was used to isolate the $\operatorname{Lp}(\mathrm{a})$ particles in the second series of studies, even though it has been demonstrated that not all plasma $\mathrm{Lp}(\mathrm{a})$ binds effectively to lysine-sepharose. However, this method of isolation is unlikely to have biased the conclusion, because the majority of the $\operatorname{Lp}(\mathrm{a})$ bound to the lysine-sepharose and because $\mathrm{Lp}(\mathrm{a})$ containing the two different isoforms were isolated in exactly the same fashion and injected back into the same individual. Third, radioiodination could theoretically modify the $\mathrm{Lp}(\mathrm{a})$ particles and obscure the ability to detect differences in catabolic rates among apo(a) isoforms. Although this possibility cannot be completely excluded, there is a variety of evidence to suggest that radiolabeling does not significantly affect $\mathrm{Lp}(\mathrm{a})$ kinetics. $(a)$ There is no evidence by SDS-PAGE or agarose electrophoresis that $\mathrm{Lp}(\mathrm{a})$ is altered in its physical properties; $(b)$ there are data from endogenous labeling of other apolipoproteins, such as apoA-I (29) and VLDL and LDL apoB (30) that radioiodination does not substantially affect their metabolism; and $(c) \mathrm{Lp}(\mathrm{a})$ turnover rates in several different laboratories using different iodination methods have been consistent with each other and are generally somewhat slower than LDL turnover rates. The final potential limitation is that laser densitometry of plasma apo(a) immunoblots may not be absolutely quantitative, and therefore the isoform-specific $\mathrm{Lp}(\mathrm{a})$ production rates in Table III may not be quantitatively accurate. Nevertheless, the basic conclusion-that a difference in $\mathrm{Lp}(\mathrm{a})$ production rates, not catabolic rates, is the basis for the difference in plasma concentrations among the apo(a) isoforms-is not changed.

The cellular mechanism of the inverse association of apo(a) size with rate of $L p(a)$ production remains to be established. The size polymorphism may be linked to other cis-acting factors which determine the rate of apo(a) gene transcription (31). Alternatively, the apo(a) size polymorphism could directly modulate apo(a) gene transcription, apo(a) mRNA stability, apo(a) protein translation, apo(a) posttranslational stability, or $\mathrm{Lp}(\mathrm{a})$ particle assembly and secretion. Azrolan et al. (32) reported that in a cynomolgus monkey model hepatic apo(a) mRNA transcript length did not correlate with hepatic apo(a) mRNA abundance. However, Wade et al. (33) reported that in human liver the size of the apo(a) mRNA transcripts was inversely correlated with apo(a) mRNA concentration. In both studies, variation in hepatic apo(a) mRNA abundance did not account for the majority of the variation in plasma $L p(a)$ concentrations. Recently, White et al. (34) reported that in baboon hepatocytes there was significant variation in apo (a) secretion rates among different apo(a) isoforms. Therefore, the size of the apo(a) isoprotein may affect its posttranslational intracellular metabolism before secretion.

In summary, the apo(a) size polymorphism does not substantially influence the plasma catabolic rate of $\operatorname{Lp}(a)$ in hu- mans. This finding directs further investigation to the cellular basis of the inverse association between the apo(a) size polymorphism and the production rate of $\mathrm{Lp}(\mathrm{a})$.

\section{Acknowledgments}

We would like to thank Marie Kindt for excellent technical assistance, Betty Kuzmik and National Institutes of Health Clinical Center nursing staff for care of the study subjects, and the subjects who volunteered for these studies.

\section{References}

1. Scanu, A. M., and G. M. Fless. 1990. Lipoprotein (a). Heterogeneity and biological relevance. J. Clin. Invest. 85:1709-1715.

2. Loscalzo, J. 1990. Lipoprotein (a). A unique risk factor for atherothrombotic disease. Arteriosclerosis. 10:672-679.

3. Sandkamp, M., H. Funke, H. Schulte, E. Kohler, and G. Assmann. 1990. Lipoprotein ( $\mathrm{a}$ ) is an independent risk factor for myocardial infarction at a young age. Clin. Chem. 36:20-23.

4. Rosengren, A., L. Wilhelmsen, E. Eriksson, B. Risberg, and H. Wedel. 1990. Lipoprotein (a) and coronary heart disease: a prospective case-control study in a general population sample of middle aged men. Br. Med. J. 301:12481251.

5. Sandholzer, Ch., E. Boerwinkle, N. Saha, M. C. Tong, and G. Utermann. 1992. Apolipoprotein (a) phenotypes, $\operatorname{Lp}$ (a) concentration and plasma lipid levels in relation to coronary heart disease in a Chinese population: evidence for the role of the apo (a) gene in coronary heart disease. J. Clin. Invest. 89:1040-1046.

6. Sigurdsson, G., A. Baldursdottir, H. Sigvaldason, U. Agnarsson, G. Thorgeirsson, and N. Sigfusson. 1992. Predictive value of apolipoproteins in a prospective survey of coronary artery disease in men. Am. J. Cardiol. 69:1251-1254.

7. Dahlen, G. H., J. R. Guyton, M. Attar, J. A. Farmer, J. A. Kautz, and A. M. Gotto, Jr. 1986. Association of levels of lipoprotein Lp(a), plasma lipids, and other lipoproteins with coronary artery disease documented by angiography. Circulation. 74:758-765.

8. Armstrong, V. W., P. Cremer, E. Eberle, A. Manke, F. Schulze, H. Wieland, H. Kreuzer, and D. Seidel. 1986. The association between serum $\operatorname{Lp}(\mathrm{a})$ concentrations and angiographically assessed coronary atherosclerosis. Dependence on serum LDL levels. Atherosclerosis. 62:249-257.

9. Seed, M., F. Hoppichler, D. Reaveley, S. McCarthy, G. R. Thompson, E. Boerwinkle, and G. Utermann. 1990. Relation of serum lipoprotein (a) concentration and apolipoprotein(a) phenotype to coronary heart disease in patients with familial hypercholesterolemia. $N$. Engl. J. Med. 322:1494-1499.

10. Rhoads, G. G., G. Dahlen, K. Berg, N. E. Morton, and A. L. Dannenberg. 1986. $\mathrm{Lp}$ (a) lipoprotein as a risk factor for myocardial infarction. JAMA 256:2540-2544.

11. Genest, J. J., Jr., S. S. Martin-Munley, J. R. McNamara, J. M. Ordovas, J. Jenner, R. H. Myers, S. R. Silberman, P. W. F. Wilson, D. N. Salem, and E. J. Schaefer. 1992. Familial lipoprotein disorders in patients with premature coronary artery disease. Circulation. 85:2025-2033.

12. Durrington, P. N., M. Ishola, L. Hunt, S. Arrol, and D. Bhatnagar. 1988. Apolipoproteins (a), AI, and B and parental history in men with early onset ischaemic heart disease. Lancet. 1:1070-1073.

13. Fless, G. M., C. A. Rolih, and A. M. Scanu. 1984. Heterogeneity of human plasma lipoprotein (a). Isolation and characterization of the lipoprotein subspecies and their apoproteins. J. Biol. Chem. 259:11470-11478.

14. Gaubatz, J. W., C. Heideman, A. M. Gotto, Jr., J. D. Morrisett, and G. H. Dahlen. 1983. Human plasma lipoprotein [a]. Structural properties. J. Biol. Chem. 258:4582-4589.

15. Fless, G. M., M. E. ZumMallen, and A. M. Scanu. 1985. Isolation of apolipoprotein (a) from lipoprotein(a). J. Lipid Res. 26:1224-1229.

16. Trieu, V. N., T. F. Zioncheck, R. M. Lawn, and W. J. McConathy. 1991. Interaction of apolipoprotein(a) with apolipoprotein B-containing lipoproteins. J. Biol. Chem. 266:5480-5485.

17. Utermann, G. 1989. The mysteries of lipoprotein(a). Science (Wash. DC). 246:904-910.

18. Boerwinkle, E., C. C. Leffert, J. Lin, C. Lackner, G. Chiesa, and H. H Hobbs. 1992. Apolipoprotein (a) gene accounts for greater than $90 \%$ of the variation in plasma lipoprotein (a) concentrations. J. Clin. Invest. 90:52-60.

19. Utermann, G., H. J. Menzel, H. G. Kraft, H. C. Duba, H. G. Kemmler, and C. Seitz. 1987. $\mathrm{Lp}(\mathrm{a})$ glycoprotein phenotypes. Inheritance and relation to Lp (a)-lipoprotein concentrations in plasma. J. Clin. Invest. 80:458-465.

20. Reblin, T., D. J. Rader, U. Beisiegel, H. Greten, and H. B. Brewer, Jr. 1992. Correlation of apolipoprotein (a) isoproteins with $\operatorname{Lp}(\mathrm{a})$ density and distribution in fasting plasma. Atherosclerosis. 94:223-232. 
21. Kraft, H. G., C. Sandholzer, H. J. Menzel, and G. Utermann. 1992. Apolipoprotein (a) alleles determine lipoprotein(a) particle density and concentration in plasma. Arterioscler. Thromb. 12:302-306.

22. Rader, D. J., W. Cain, L. A. Zech, D. Usher, and H. B. Brewer, Jr. 1993. Variation in lipoprotein (a) concentrations among individuals with the same apolipoprotein (a) isoform is determined by the rate of lipoprotein (a) production. $J$. Clin. Invest. 91:443-447.

23. Berman, M., and M. Weiss. 1978. In SAAM Manual, DHEW Publ. No. (NIH) 78. National Institutes of Health, Bethesda, MD.

24. Neville, D. M., Jr. 1971. Molecular weight determination of protein-dodecyl sulfate complexes by gel electrophoresis in a discontinuous buffer system. $J$. Biol. Chem. 246:6328-6334.

25. Bojanovski, M., R. E. Gregg, D. M. Wilson, and H. B. Brewer, Jr. 1987. Semi-automated enzyme-linked immunosorbent assay (ELISA) for the quantifcation of apolipoprotein B using monoclonal antibodies. Clin. Chim. Acta. 170:271-280.

26. Fless, G. M., M. L. Snyder, and A. M. Scanu. 1989. Enzyme-linked immunoassay for Lp[a]. J. Lipid Res. 30:651-662.

27. Krempler, F., G. Kostner, K. Bolzano, F. Sandhofer. 1980. Turnover of Lipoprotein (a) in man. J. Clin. Invest. 65:1483-1490.

28. Knight, B. L., Y. F. N. Perombelon, A. K. Soutar, D. P. Wade, and M Seed. 1991. Catabolism of lipoprotein (a) in familial hypercholesterolaemic subjects. Atherosclerosis. 87:227-237.
29. Ikewaki, K., D. J. Rader, J. R. Schaefer, T. Fairwell, L. A. Zech, and H. B. Brewer, Jr. 1993. Evaluation of apoA-I kinetics in humans using simultaneous endogenous stable isotope and exogenous radiotracer methods. J. Lipid Res. 34:2207-2215.

30. Parhofer, K. G., P. H. R. Barrett, D. M. Bier, and G. Schonfeld. 1991. Determination of kinetic parameters of apolipoprotein B metabolism using amino acids labeled with stable isotopes. J. Lipid Res. 32:1311-1323.

31. Kraft, H. G., S. Köchl, H. J. Menzel, C. Sandholzer, and G. Utermann. 1992. The apolipoprotein (a) gene: A transcribed hypervariable locus controlling plasma lipoprotein (a) concentration. Hum. Genet. 90:220-230.

32. Azrolan, N., D. Gavish, and J. L. Breslow. 1991. Plasma lipoprotein(a) concentration is controlled by apolipoprotein (a) (Apo(a)) protein size and the abundance of hepatic Apo(a) mRNA in a cynomolgus monkey model. J. Biol. Chem. 266:13866-13872.

33. Wade, D. P., B. L. Knight, K. Harders-Spengel, and A. K. Soutar. 1991. Detection and quantitation of apolipoprotein (a) mRNA in human liver and its relationship with plasma lipoprotein(a) concentration. Atherosclerosis. 91:6372.

34. White, A. L., D. L. Rainwater, J. E. Hixson, and R. E. Lanford. 1992. $\mathrm{Lp}$ (a) assembly and the influence of allelic variation on apo(a) secretion. Circulation. 86:I-424. (Abstr.) 